\title{
Divergence in Pigmentation as a Result of Wet Forests in an Insular Population of Flameback Woodpeckers
}

\author{
Ranasinghe R.W., Seneviratne S.S.* \\ ${ }^{1}$ Avian Evolution Node, Department of Zoology \& Environment Sciences, University of \\ Colombo, Sri Lanka \\ *sam@sci.cmb.ac.lk
}

\begin{abstract}
Sri Lanka's wet zone forests are considered as the wettest tropical forests in the South Asian region. Within the island of Sri Lanka, the wet zone forests are darker and wetter than its dry zone counterpart. The woodpecker genus Dinopium flamebacks has a distinctive yellow color plumage across its range except in the Sri Lankan wet zone. Here in the wet zone they show an endemic red coloration. According to the Gloger's rule, animals become darkly colored in habitats where relative humidity is high and pale colored where humidity is low. Hence we checked, whether these dark environment in wet zone forests contribute to the evolution of woodpecker plumage coloration in Sri Lanka. We measured Plumage reflectance spectra of 18 live flamebacks 58 skin samples $(29$ D. psarodes-red, 16 D. benghalense-yellow and 13 hybrids - orange) using a miniature spectrometer together with a light source of spectral range 375-700 nm. The pigments from mantle feathers of this same samples were extracted under mild conditions into different polar solvents. Extractions were analyzed by using UV-visible absorption spectroscopy, TLC and HPLC. A subset of mantle feathers were also analysed using ATR-FTIR spectrometry. Yellow and red feathers showed reflectance peaks at $\sim 510 \mathrm{~nm}$ and $\sim 575 \mathrm{~nm}$ wavelengths respectively. Polar solvents (chloroform, ethyl acetate and methanol) produce the characteristic carotenoid absorbance spectra therefore xanthophyll pigments are responsible for flameback colorations. TLC and HPLC chromatograms and ATRFTIR spectrograms showed two sets of bands (TLC) or peaks (HPLC and ATR-FTIR) in red feathers, however yellow feathers had a single set of bands or peaks corresponding the yellow color. Our results showed a new endemic pigment molecule in red color woodpeckers. This new pigment molecule is absent in yellow flameback feathers. A reduced concentration of endemic pigment produce the orange coloration in genetic hybrids in a narrow hybrid zone ranges from Puttulum to Mulativu. Since the darker environment in wet zone might favor dark birds and light environment in the dry zone and in the rest of the mainland favor light color birds, here we showed evidence for divergence of acarotenoid pigmentas a response to the dark wet zone forests that caused the absorbance of yellow color and express red color, triggering a speciation event that adds an endemic species to the island of Sri Lanka.
\end{abstract}

Keywords: Carotenoids, Dinopium, Divergence, Pigment ecology, Sri Lanka

Proceedings of the $22^{\text {nd }}$ International Forestry and Environment Symposium 2017 of the Department of Forestry and Environmental Science, University of Sri Jayewardenepura, Sri Lanka 